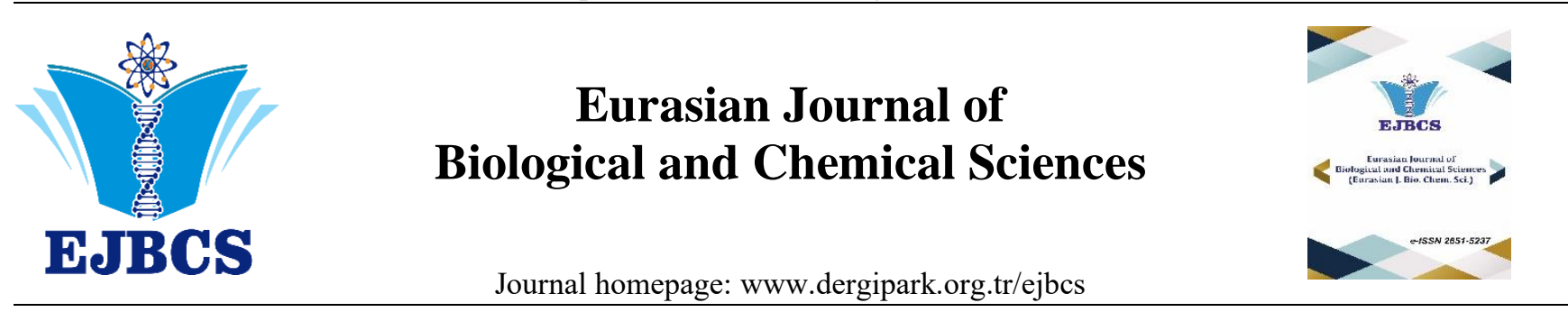

\title{
Tilmikosin Zehirliliği: Mini Derleme
}

\author{
Rahmi Canbar ${ }^{D}$, Enver Yazar*iD \\ *Selçuk Üniversitesi, Veteriner Fakültesi, Farmakoloji ve Toksikoloji Anabilim Dalı Selçuklu, Konya, Türkiye,
}

Özet: Tilmikosin sadece veteriner hekimlik için geliştirilmiş makrolid grubu antibiyotiktir. Ürünün kullanımı sığır, koyun, domuz, hindi ve tavuklarda onaylanmıştır. Etkili olduğu mikroorganizmalarda protein sentezini engelleyerek bakteriostatik etki gösterir. $\mathrm{Bu}$ hayvanlarda özellikle solunum sistemi enfeksiyonlarının tedavisinde kullanılır. Makrolid grubu antibiyotiklerin yan etkileri arasında tanımlanan kardiyotoksisite ise tilmikosinde oldukça belirgindir. Etiket dışı kullanımda veya kullanımı önerilen hayvanlarda deri altı dışı uygulamalarda ölüme kadar gidebilen kardiyotoksisiteye neden olabilmektedir. İnsanlar ise genellikle tilmikosine kazara maruz kalırlar ve ölümler gözlenebilmektedir. Veteriner ilaçlar arasında en fazla yan etki bildirilen ilaçlardan birisidir. Bu derlemede tilmikosinin insan ve hayvanlarda neden olduğu toksisitesi, mekanizması ve tedavi seçenekleri hakkında bilgi verilmeye çalışılmıştır.

Anahtar kelimeler: Tilmikosin, kardiyotoksisite, zehirlilik

\section{Tilmicosin Toxication: Mini Review}

\begin{abstract}
Tilmicosin is a macrolide group antibiotic developed only for veterinary medicine. The use of the product is approved in cattle, sheep, pigs, turkeys and chickens. It shows bacteriostatic effect by inhibiting protein synthesis in microorganisms. They are especially used in the treatment of respiratory system infections in these animals. Cardiotoxicity, which is defined among the side effects of macrolide group antibiotics, is quite prominent in tilmicosin. It can cause cardiotoxicity and death, when non-subcutaneous applications in recommended animals or extra-label use. Humans can often be accidentally exposed to tilmikosin, and deaths can be observed. Tilmicosin is one of the most reported side effects among veterinary drugs. In this review, it could be tried to give information about the toxicity, mechanism and treatment options of tilmicosin in humans and animals.
\end{abstract}

Keywords: Tilmicosin, cardiotoxicity, toxicity

(c) EJBCS. All rights reserved.

\section{Giriş}

Makrolid grubu antibiyotikler veteriner hekimlikte en fazla kullanılan antibiyotiklerdendir. Hedef tür hayvanlarda solunum sistemi enfeksiyonları, anerob enfeksiyonlar ve ayak enfeksiyonlarının tedavisinde sıklıkla kullanılırlar. Etkili oldukları mikroorganizmalarda protein sentezini engelleyerek bakteriostatik etki gösterirler. Makrolid grubu antibiyotiklerden eritromisin, tilosin, tilvalosin, spiramisin, tilmikosin, tulatromisin, gamitromisin ve tildipirosin veteriner hekimlikte kullanım alanı bulur (Yazar, 2018; Yazar, 2020; Coskun ve Yazar, 2020). Tilmikosin kullanımında hedef tür olarak sığır, koyun, domuz, hindi ve tavuklar tanımlanmıştır. $\mathrm{Bu}$ hayvanlarda özellikle Pasteurella multocida ve Mannheimia (Pasteurella) haemolytica kaynaklı solunum sistemi enfeksiyonları tedavisinde kullanılır. Sığır ve koyunlarda önerilen tek dozda $(10 \mathrm{mg} / \mathrm{kg}$, deri altı) etkinliğini yaklaşık olarak üç gün koruduğu, gerek duyulduğunda üç gün sonra tekrar uygulama yapılabileceği ifade edilmektedir (Yazar, 2018; EMA, 2020a; EMA, 2020b).

Deneysel araştırmada makrolid grubu antibiyotiklerin kardiyotoksik etkiler gösterebileceği belirlenmiştir (Yan ve ark., 2019). Tilmikosin veteriner hekimlikte yaygın olarak kullanılsa da ölümle sonuçlanabilen ciddi kardiyotoksik yan etkiler gösterebilmektedir. Enjektabl ticari formulasyon sadece deri altı yolla uygulanır. Türe bağlı olarak değişmekle birlikte $7.5-30 \mathrm{mg} / \mathrm{kg}$ (IM, IV) dozlarında ölümlere neden olabildiği belirtilmiştir (Yazar, 2020; EMA, 2020a). 


\section{Tilmikosin Zehirliliği}

Yapılan araştırmalarda tilmikosinin apoptozis (Oda ve Derbalah, 2018) veya oksidatif strese (Aboubakr ve ark., 2020) neden olarak kardiyotoksisiteye neden olabileceği ifade edilse de, kardiyotoksik etkilerini pozitif kronotropi ve negatif inototropiye neden olarak gösterir (Yazar, 2020; EMA, 2020a). Tilmikosinin kardiyotoksik etkileri hayvanlarda rapor edilmekle (Arunvikram ve ark., 2014; Yazar, 2020) birlikte, insanlarda da ölümlere kadar gidebilen zehirlenme vakaları bildirilmiştir (Oakes ve Seifert, 2008). Tilmikosin kaynaklı zehirlenme vakaları insanlarda kazara, mesleki maruziyet ve intihar kaynaklı olarak gözlenebilmektedir. Tilmikosin ve taşıt maddesi olan propilen glikolün insanlar için özellikle intravenöz uygulamada oldukça zehirli olabileceği ifade edilmiştir. Kardiyotoksik etkisini ise kalsiyum kanallarını bloke ederek gösterebileceği belirlenmiştir. Dermal kontaminasyonda emilimin azaltılması için deriye buz uygulaması önerilmektedir. Sistemik maruz kalmalarda ise damar içi kalsiyum, dopamin veya doputamin uygulamaları yapılabileceği ifade edilmiştir. Beta blokörler, adrenalin veya noradrenalin uygulaması yapılmamalıdır (Lust ve ark., 2011). Amerika Birleşik Devletlerinde 2001-2005 yılları arasında 1.291 insanın tilmikosine maruz kaldığı ifade edilmiştir. Parenteral yolla maruz kalmayan insanlarda ciddi yan etkiler veya ölüm gözlenmezken, parenteral yolla maruz kalanlarda ciddi yan etkiler ve ölümler gözlendiği bildirilmiștir. Parenteral $0.5 \mathrm{~mL}$ dozunda maruziyette ciddi yan etkiler gözlenebileceği ifade edilmiştir (Oakes ve Seifert, 2008). Tilmikosin zehirliliği ile ilgili farmakovijilans raporuna göre ilaca maruz kalan 3.168 insanın yaklaşık yarısında klinik belirti görülmediği ve enjeksiyonların büyük kısmının kazara yapıldığı bildirilmiş̧ir. Klinik belirtilerin ilk bir saat içinde geliştiği, yaygın klinik belirti olarak enjeksiyon yerinde ağrı, kanama, şişme, bulant, taşikardi, anksiyete, baş dönmesi ve göğüs ağrısı gözlendiği bildirilmiştir. İlaca maruz kalan 156 kişide ciddi yan etkiler gözlendiği ve 13 vakada ölüm geliştiği ifade edilmiştir. Ölümlerin 11 tanesinin intihardan, 2 tanesinin ise kazara enjeksiyondan kaynaklandığı rapor edilmiştir (Veenhuizen ve ark., 2006). Ayrıca 1998-2003 yılları arasinda tilmikosine maruz kalan 46 insanda ölüm gözlenmediği ifade edilmiştir (Forrester, 2005). Kazara tilmikosin enjeksiyonuna maruz kalan bir insan ile ilgili yayınlanan vaka raporunda ciddi göğüs ağrısı, EKG'de değişim, kalp enzimlerinde yükselmeler gözlendiği ve tilmikosin uygulamasının eğitimli personelce yapılması gerektiği ifade edilmiştir (Von Essen ve ark., 2003). Kazara maruziyete kalan başka bir vakada solunum güçlüğü, taşikardi ve hipotansiyon geliştiği bildirilmiştir. Tedavide parenteral kalsiyum, insülin, dektroz ve intravenöz lipid emülsiyonu uygulamalarının faydalı olabileceği ifade edilmiştir (Besserer ve ark., 2016).

İnsanların yanında hayvanlarda da toksisite raporları bildirilmiştir. Sunulan vaka raporlarında tilmikosine bağlı keçi (Coskun ve ark., 2012) ve kuzu (Christodoulopoulos, 2009) ölümleri rapor edilmiştir. Özellikle keçilerde çok zehirli olmasına rağmen, primatlar dahil diğer türlerde toksik etkiler gösterebilmektedir. Maymunlarda ölüm dozunun yaklaşı $30 \mathrm{mg} / \mathrm{kg}$ olduğu, satılan ticari ürünlerden $(300 \mathrm{mg} / \mathrm{mL}) 6 \mathrm{~mL}$ 'sinin ölüme neden olabileceği bildirilmiştir (Yazar, 2020). Merkeplere deneysel amaçlı tilmikosin uygulaması sonrasinda ekokardiyografide kısa süreli değişimlere neden olduğu ifade edilmiştir (Youssef ve ark., 2016). Köpeklerde yapılan araştırma tilmikosinin negatif inotropi ve taşikardiye neden olduğu, beta blokör uygulamasının olumlu etkisinin olmadığı, ancak doputamin uygulamasının kısmen olumlu etkileri olduğu ifade edilmiştir (Main ve ark., 1996). Deneysel olarak Mycoplasma spp ile enfekte domuzlara farklı dozlarda oral tilmikosin uygulamasının biyokimyasal ve fizyolojik parametrelere olumsuz etkilerinin olmadığı bildirilmiştir (Zhang ve ark., 2018).

Yapılan araştırmalarda tilmikosin uygulamasının tavşanlarda alyuvar ve akyuvar sayısında geçici düşme dışında, hemogram ile serum biyokimyasal parametreleri etkilemediği (Altunok ve ark., 2002), karaciğer ve böbrek fonksiyon parametreleri üzerine belirgin olumsuz etkileri olmadığ (Said ve ark., 2016), ancak kalp hasarı belirteçleri olan kreatin kinaz, kreatin kinaz-MB ve troponin I düzeylerinde artışa neden olduğu ifade edilmiştir. Tilmikosinin kardiyotoksik etkilerinin net olarak tanımlanması için histopatolojik değerlendirme de yapılması gerektiği belirtilmiştir (Yazar ve ark., 2002b).

Ratlarda yapılan araştırmalarda letal doz tilmikosin $(360$ $\mathrm{mg} / \mathrm{kg}, \mathrm{SC}$ ) uygulamasından 8 dakika sonra amiodaron (25 $\mathrm{mg} / \mathrm{kg}$, IV) uygulamasının, tek başına tilmikosin uygulanan gruba göre hayatta kalma oranını $\% 0$ 'dan $\% 40$ yükselttiği ve tilmikosin zehirlenmesinde kullanılabileceği (Er ve ark., 2014), tilmikosinin neden olduğu myokardial oksidatif stres (Cetin ve ark., 2011), laktat dehidrogenaz, kreatin kinaz, kreatin kinaz-MB düzeylerinde artışlar ve sol ventriküler sistolik disfonksiyona (Cetin, 2019) ghrelin uygulamasının olumlu etkiler gösterebileceği ifade edilmiştir. Yüksek doz tilmikosin uygulaması sonrasında kalp hasarı belirteçleri ile malondialdehid düzeyinin yükseldiği, antioksidan parametrelerde düşmeler ve histopatalojide yoğun yangı hücre infiltrasyonu ve nekrozlar gözlendiği belirtilmiştir. Tilmikosinin neden olduğu kardiyotoksisitede karnitin ve/veya vitamin E uygulamalarının olumlu etkileri olabileceği ifade edilmiştir (Aboubakr ve ark., 2020). Gebe ratlara yüksek dozlarda tilmikosin uygulamasının fetal defekt ile anormalliklere neden olduğu ve gebelikte kullanımının riskli olabileceği belirtilmiştir (Abo-Kora ve ark., 2016).

Farelerde yapılan araştırmalarda tilmikosin uygulamasının hemogram parametrelerini değiştirmediği, kalpte lipid peroksidasyonuna neden olmadığı, ancak yüksek dozlarda karaciğer malondialdehid (Yazar ve ark., 2004), serum kreatin kinaz, kreatin kinaz-MB, malondialdehid (Yapar ve ark., 2006), kardiyak kreatin kinaz (Yazar ve ark., 2001), karaciğer, böbrek ve kalp hasarı parametrelerini yükselttiği (Gheith ve ark., 2015), hemogram parametreleri (Gheith ve ark., 2015), kardiyak süperoksit dismutaz ve glutasyon peroksidaz düzeyini düşürdüğü bildirilmiştir (Yazar ve ark., 2002a). Tilmikosinin neden olduğu kardiyotoksisite ve lipid peroksidasyonunun düzeltilmesi üzerine Spirulina platensis (Ibrahim ve Abdel-Daim, 2015) veya L-karnitin (Kart ve 
ark., 2007a; Kart ve ark., 2007b) uygulamalarının olumlu etkileri olduğu ifade edilmiştir.

Tilmikosinin kanatlilarda histolojik ve biyokimyasal parametreler üzerine belirgin etkisinin bulunmadığ 1 (Rasheed ve ark., 2018), oksidatif stres (Eraslan, 2007), hematolojik ve biyokimyasal parametrelerde geçici değişimlere neden olabileceği ifade edilmiştir (Elsayed ve ark., 2014).

\section{Sonuç ve Öneriler}

Tilmikosin veteriner hekimlikte özellikle sığırlarda çok sık kullanılmaktadır. Solunum sistemi enfeksiyonlarında tedavi maliyeti olarak uygun olsa da ölümle sonuçlanabilen kardiyotoksik yan etkiler gelişebilmektedir. İlaç uygulayacak eğitimli personel bulunmadığı durumlarda, tedavide diğer alternatif antibiyotikler değerlendirilebilir. Literatür taramasından anlaşılabileceği gibi ilaç hayvanlar kadar insanlarda da ciddi yan etkilere neden olabilmektedir. Gelișen kardiyotoksisite kalsiyum kanalları inhibisyonu yanında oksidatif stres ve apoptozis ile ilişkilendirilse de literatürde fikir birlikteliği bulunmamaktadır. Gelişen ölüm hızı dikkate alındığında sadece oksidatif stresle açıklamak yeterli değildir. Tedavide ise zehirlenme vakalarında genel refleks olarak ilk uygulaması düşünülen atropin, beta blokör, adrenalin (epinefrin) veya noradrenalin (norepinefrin) bu vakalarda uygulanmamalıdır. Tedavide damar içi kalsiyum, amiodoran ve dopamin veya doputamin uygulamaları yanında yüksek doz insülin ve dekstroz uygulamaları önerilebilir.

\section{Kaynaklar}

Abo-Kora S, El-Meleh A, Aboubakr, M 2016. Effect of tilmicosin on fetal developments in pregnant female albino rats. Pharmacol Pharm, 7:147-152.

Aboubakr M, Elsayd F, Soliman A, Fadl SE, El-Shafey A, Abdelhiee E.Y 2020. L-Carnitine and vitamin E ameliorate cardiotoxicity induced by tilmicosin in rats. Environ Sci Pollut Res Int, 27:23026-23034.

Altunok V, Yazar E, Elmas M, Tras B, Bas AL, Col R 2002. Investigation of haematological and biochemical side effects of tilmicosin in healthy New Zealand rabbits. J Vet Med B, 49:68-70.

Arunvikram K, Mohanty I, Sardar KK, Palai S, Sahoo G, Patra RC 2014. Adverse drug reaction and toxicity caused by commonly used antimicrobials in canine practice. Vet World, 7:299-305.

Besserer F, Chuang R, Mink M, Massey L, Cload B 2016. Tilmicosin toxicity: a case of accidental human tilmicosin injection managed with calcium, high-dose insulin and intravenous lipid emulsion therapy. Clin Toxicol, 54:812-813.

Cetin E 2019. Protective effect of ghrelin against tilmicosininduced left ventricular dysfunction in rats. Can $\mathrm{J}$ Physiol Pharm, 97:407-412.

Cetin N, Boyraz U, Cetin E 2011. Ghrelin alleviates tilmikosin induced myocardial oxidative stress in rats. JAVA, 10:2038-2042
Christodoulopoulos G 2019. Adverse outcome of using tilmicosin in a lamb with multiple ventricular septal defects. Can Vet J, 50:61-63.

Coskun D, Yazar E 2020. Use of tildipirosin in ruminants. Eurasian J Bio Chem Sci, 3:70-73.

Coskun Y, Golen I, Ondes S, Erdogdu T 2012. Poisoning case caused by tilmicosin in goats. Bornova Vet Bil Derg, 34:39-42.

Elsayed M, Elkomy A, Aboubakr M, Morad M 2014. Tissue residues, hematological and biochemical effects of tilmicosin in broiler chicken. Vet Med Int, 502872.

EMA 2020a.

https://www.ema.europa.eu/en/documents/mrlreport/tilmicosin-extension-turkeya-summary-report6-committee-veterinary-medicinal-products_en.pdf, erișim tarihi:07.08.2020

EMA

https://www.ema.europa.eu/en/documents/mrl$2020 b$ report/tilmicosin-pigs-sheep-tissues-summary-report2-committee-veterinary-medicinal-products_en.pdf, erişim tarihi:07.08.2020

Er A, Tras B, Cetin G, Dik B 2014. Amiodarone may prevent the tilmicosin-caused lethal toxicity. Acta Sci Vet, 42:1187.

Eraslan G 2007. Effects of different doses of tilmicosin on erythrocyte catalase activity and plasma malondialdehyde levels in chicks. Bull Vet Inst Pulawy, 51:145-147.

Forrester MB 2005. Human exposures to tilmicosin reported to poison centres, Texas, 1998-2003. Hum Exp Toxicol, 24:275-278.

Gheith I, El-Mahmoudy A, Elmajdoub A, Awidat S 2015. Pharmacovigilance of tilmicosin in mice. Acta Sci Vet, 43:1318.

Ibrahim A, Abdel-Daim MM 2015. Modulating effects of Spirulina platensis against tilmicosin-induced cardiotoxicity in mice. Cell J, 17:137-144.

Kart A, Yapar K, Karapehlivan M, Citil M 2007a. The possible protective effect of 1-carnitine on tilmicosininduced cardiotoxicity in mice. J Vet Med A, 54:144146.

Kart A, Karapehlivan M, Yapar K, Citil M, Akpinar A 2007b. Protection through l-carnitine on tissue oxidant status and sialic acid content in tilmicosin-induced alterations in Balb/C mice. Acta Vet Brno, 76:203207.

Lust EB, Barthold C, Malesker MA, Wichman TO 2011. Human health hazards of veterinary medications: Information for emergency departments. J Emerg Med, 40:198-207.

Main BW, Means JR, Rinkema LE, Smith WC, Sarazan RD 1996. Cardiovascular effects of the macrolide antibiotic tilmicosin, administered alone and in combination with propranolol or dobutamine, in conscious unrestrained dogs. J Vet Pharmacol Therap, 19:225-232.

Oakes JA, Seifert SA 2008. American association of poison control centers database characterization of human tilmicosin exposures, 2001-2005. J Med Toxicol, $4: 225-231$. 
Oda SS, Derbalah AE 2018. Impact of diclofenac sodium on tilmicosin-induced acute cardiotoxicity in rats (tilmicosin and diclofenac cardiotoxicity). Cardiovasc Toxicol, 18:63-75.

Rasheed MA, Ashraf M, Javeed A, Anjum AA 2018. Toxicological evaluation of tilmicosin after intramuscular injection in broiler chicken. J Anim Plant Sci, 28:1678-1686.

Said, A.A., Abdel-Alim, F., El-Nabtity, S.M., Eldin, M.B., Fadel, M.A. 2016. Immunological and biochemical profiles of tilmicosin in rabbits. Zagazig Vet. J., 44, 48-55.

Veenhuizen MF, Wright TJ, McManus RF, Owens JG 2006. Analysis of reports of human exposure to Micotil 300 (tilmicosin injection). JAVMA, 229:1737-1742.

Von Essen S, Spencer J, Hass B, List P, Seifert SA, 2003. Unintentional human exposure to tilmicosin (Micotilw300). J Toxicol, 41:229-233.

Yan Z, Huang X, Xie Y, Song M, Zhu K, Ding S 2019. Macrolides induce severe cardiotoxicity and developmental toxicity in zebrafish embryos. Sci Total Environ, 649:1414-1421.

Yapar K, Kart A, Karapehlivan M 2006. Effects of different doses of tilmicosin on some biochemical parameters and antioxidant status in serum and cardiac tissues in mice. Bull Vet Inst Pulawy, 50:605-608

Yazar E 2018. Veteriner İlaç ve Aşı A'dan Z’ye, Nobel tıp yayınevi, Istanbul, Türkiye.

Yazar E 2020. Kemoterapötikler, in: Veteriner İlaç Rehberi ve Tedavi El Kitabı, Ed: Yazar E, Nobel tıp kitabevi, Istanbul, Türkiye

Yazar E, Altunok V, Elmas M, Tras B, Bas AL, Ozdemir V 2001. Effect of tilmicosin on cardiac muscle and serum creatine kinases activities and serum total protein level in healthy male Balb/C mice. Revue Med Vet, 152:881-883.

Yazar E, Altunok V, Elmas M, Tras B, Bas AL, Ozdemir V 2002a. The effect of tilmicosin on cardiac superoxide dismutase and glutathione peroxidase activities. J Vet Med B, 49:209-210.

Yazar E, Birdane YO, Elmas M, Tras B, Bas AL 2002b. Effect of tilmicosin on serum creatine kinase, creatine kinase-MB and troponin I levels in New Zealand White rabbits. Arch Geflugelk, 66:237-239.

Yazar E, Oztekin E, Sivrikaya A, Col R, Elmas M, Bas AL 2004. Effects of different doses of tilmicosin on malondialdehyde and glutathione concentrations in mice. Acta Vet Brno, 73:69-72.

Youssef MA, Ibrahim HM, Farag EM, El-Khodery SA 2016. Effects of tilmicosin phosphate administration on echocardiographic parameters in healthy donkeys (Equus asinus): an experimental study. J Equine Vet Sci, 38:24-29.

Zhang X, Pan J, Wu N, Tang S, Lei X, Sun Y, Hartung J, Bao E 2018. Investigation of the efficiency and safety of tilmicosin phosphate in treating experimental mycoplasmal infections in pigs. Turk J Vet Anim Sci, 42:571-580. 